Historic, archived document

Do not assume content reflects current scientific knowledge, policies, or practices. 


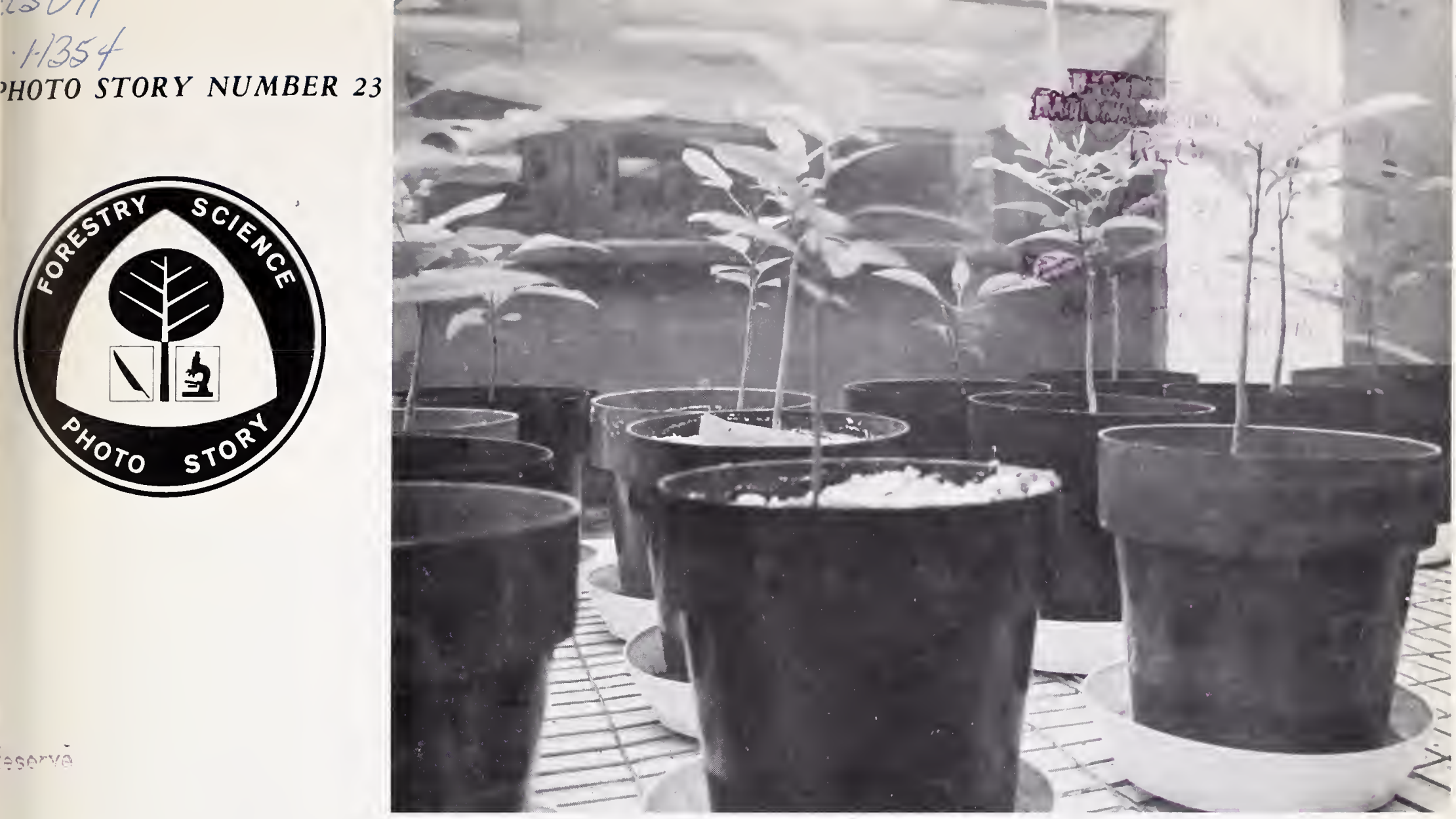

\section{Trees CHAMBERED for Air Pollution Tests}

Air pollution can affect trees! From Maine to California... from Dubrovnik to Tokyo, scientists and wise observers are continually finding more evidence that this is fact.

Going one step beyond these field observations, Forest Service researchers at the Forest Insect and Disease Laboratory in Delaware, Ohio, have launched a scientific effort to gain some insights into how various pollutants can upset a tree. Evidence already exists to show that air pollution might actually reduce the vigor of a tree by impeding its normal processes. With vigor reduced, this tree is vulnerable to attack by a host of other destructive agents, like tree insects and diseases, that could complete its demise.

As a major part of their investigation, Forest Service air pollution scientists are working with isolette-like units, called fumigation chambers, in which trees can live while their environment is controlled and monitored. Four different types of fumigation chambers have been specially fabricated for the studies.

Dr. Leon S. Dochinger, who heads the Forest Service's air pollution research work at Delaware, and Dr. Keith F. Jensen, a plant physiologist, are using the chambers in a wide variety of air pollution studies. Findings from their laboratory experimentation should lead to practical measures for application in areas where air pollution is a problem.

\section{NOTICE TO PUBLISHERS}

Information in this news bulletin may be reprinted. Please give appropriaie credit. Additional information or photographs may be obtained from: Information Services Tel-(Area Code 215) FL 2-5800, Ext-288.

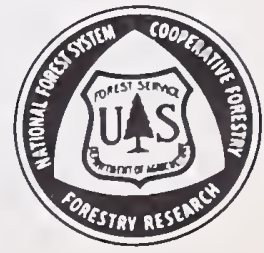


The newest, most sophisticated chambers at the Laboratory are large, 4-foot cubes. These are used mainiy to assess how trees react to various pollutants under different environmental conditions over long periods of time.

For each chamber, scientists can control air flow, temperature, humidity, and lighting to simulate a tree's normal 24-hour growing conditions. Further, chambers can be individually monitored.
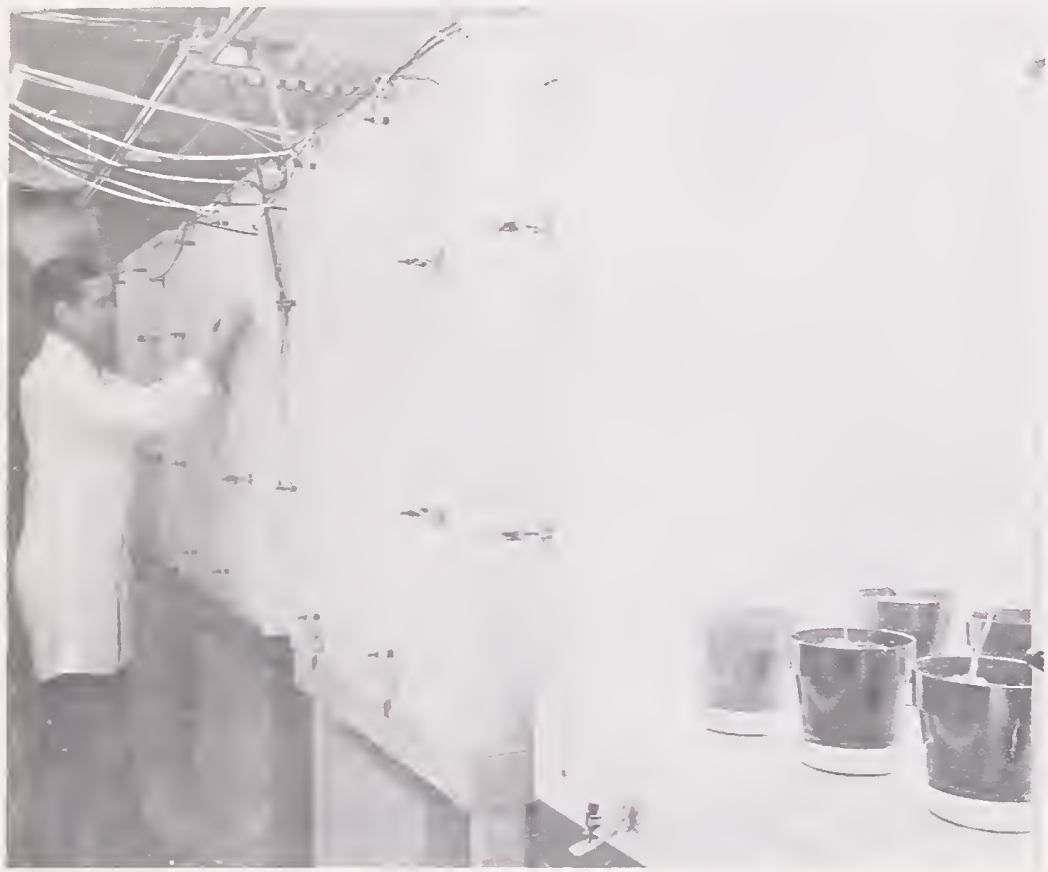

Forest Service Plant Pathologist Dr. Keith Jensen closes one of the 4-foot cubes used to test trees' reactions to pollutants under different environmental conditions. Note the bank of overhead lights and the overhead tubes, carrying pollutants into the chambers.

Artificial lighting is supplied to the chambers by a bank of overhead incandescent and fluorescent lights. A tightly-sealed, teflon cover permits lights to enter through the top of each chamber. Accompanying heaters and air conditioning equipment allow temperatures in the chambers to be controlled between 55 dearees $\mathrm{F}$. and 90 degrees $F$. Relative humidity is controlled by adding steam to the air entering each chamber.

Chamber walls are coated with epoxy paint, an inert substance, which will not break down in a polluted atmosphere as ordinary paint might.
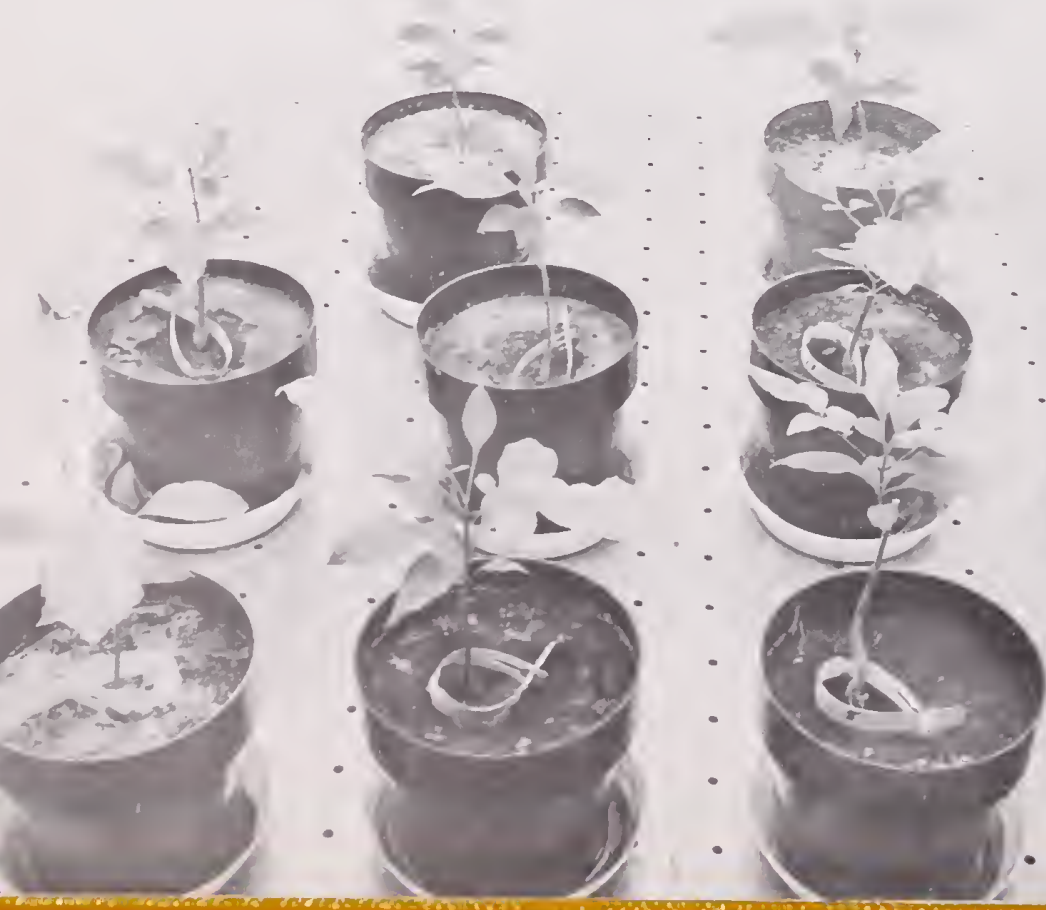

Inside the large chambers, young tree seedlings are exposed to pollutants and to environmental variations. Scientists then observe their reactions. 
In the initial tests, freshly-rooted cuttings of hybrid poplar will be arown in the chambers. They will be exposed to different amounts of sulfur dioxide and/or ozone -- the major pollutants in the U.S. air -- in different temperature, humidity, and light regimes. Scientists will then observe the reactions of the trees to note growth and yield differences, as well as any damage symptoms that might occur.

In a second set of chambers, scientists can expose seedi ings to a wide range of sulfur or ozone concentrations. Growth rates and yields, and symptoms of injury are, again, among the data scientists are interested in gathering from studies in these chambers.

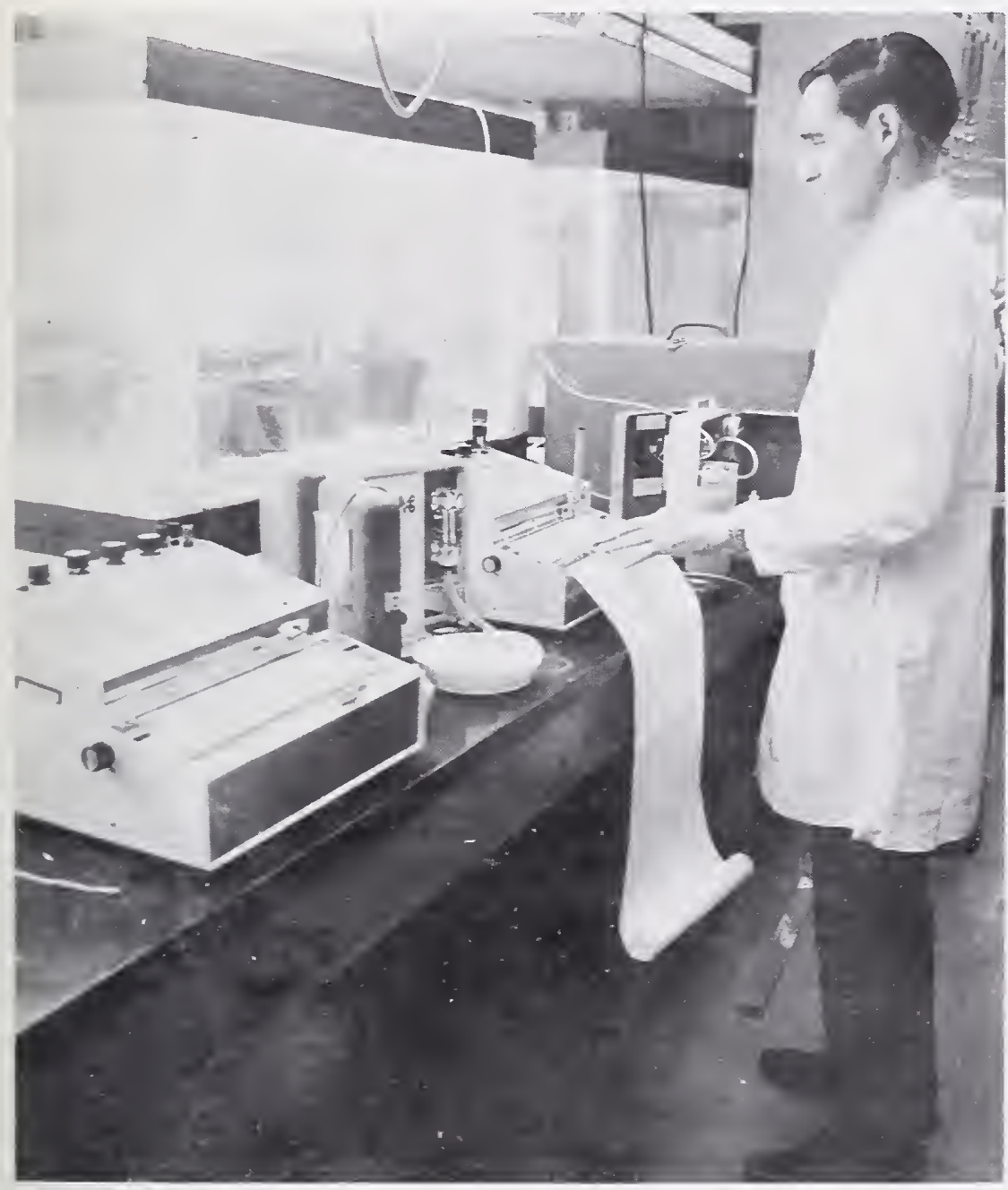

Dr. Jensen studies ozone-monitoring equipment as it measures concentrations of that pollutant inside test chambers.

AIR POLLUTION DAMAGE -- Ozone damage to ash is evidenced bu a purple cast on the top side of otherwise solid green leaves. Forest Service scientists are studying such indications of air pollution and what causes them, in hopes of developing practical measures for alleviating problems to trees.

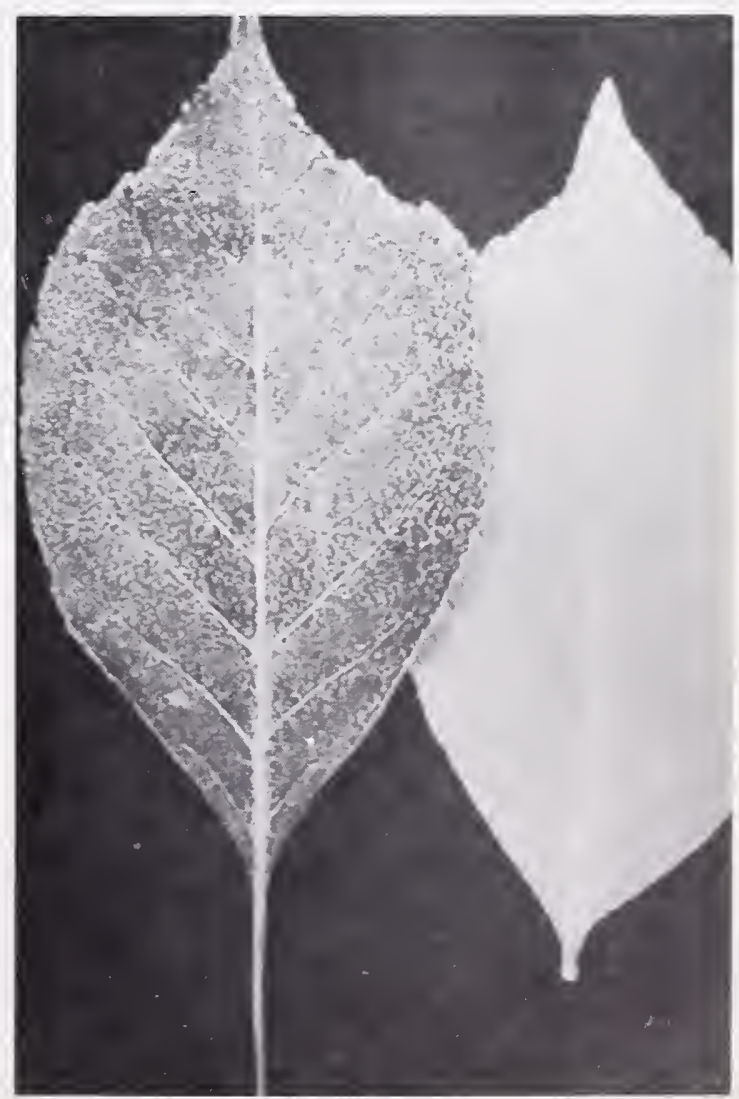


Another set of walk-in chambers is set up in a greenhouse on the grounds of the Delaware Laboratory. Larger saplings are fumigated in these chambers. These same chambers are also useful when large numbers of seedlings must be fumigated.

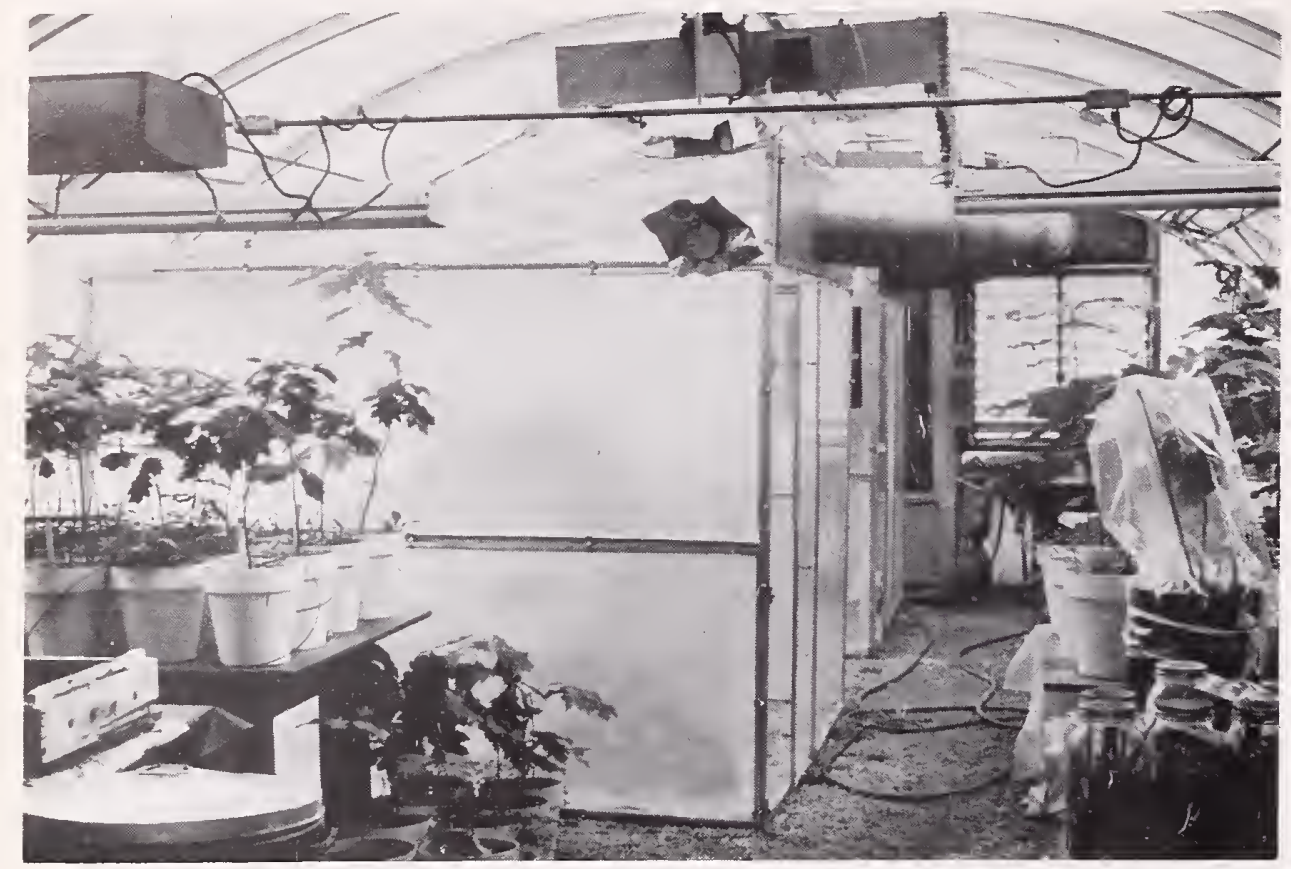

The reactions of larger trees to pollutants are being tested in a series of walk-in chambers, erected inside a greenhouse at the Forest Service's Delaware, Ohio, Laboratory.

Forest Service scientists are also using a small fumigation chamber, set inside a growth chamber, to determine what part trees play in purifying the air of pollutants.

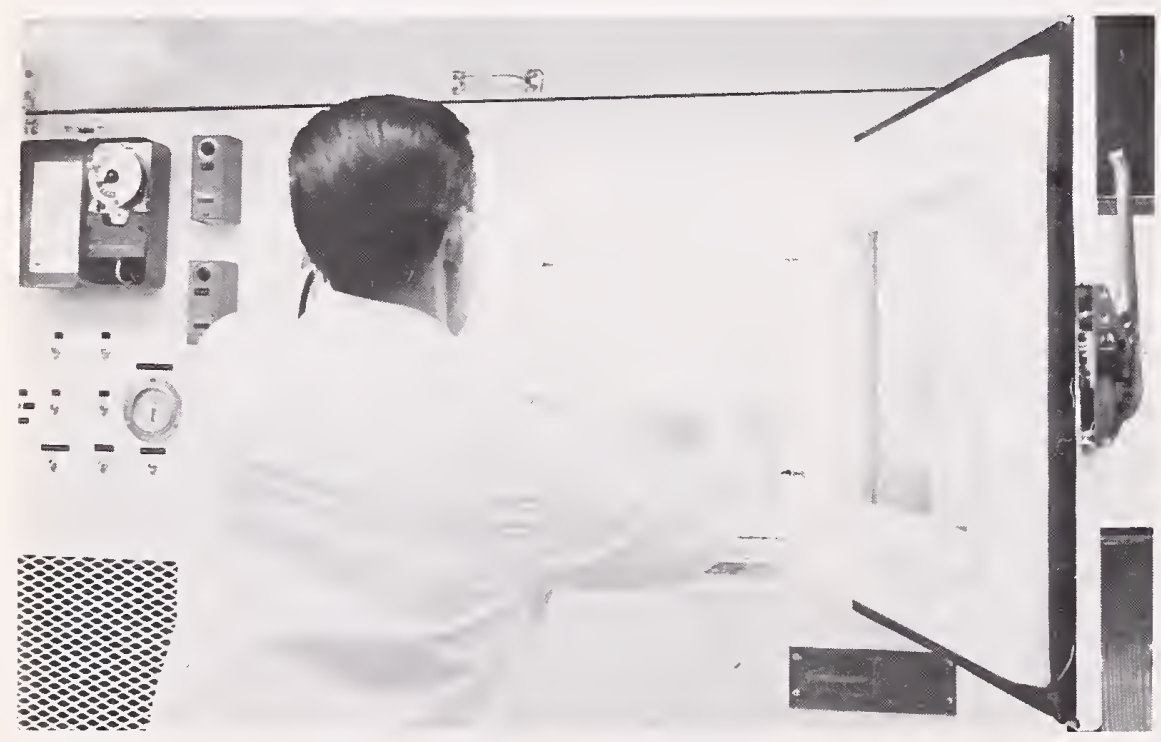

Dr: Jensen inserts a seedling into a jumigation chamber that fits into a larger growtin chamber with atmospheric controls.

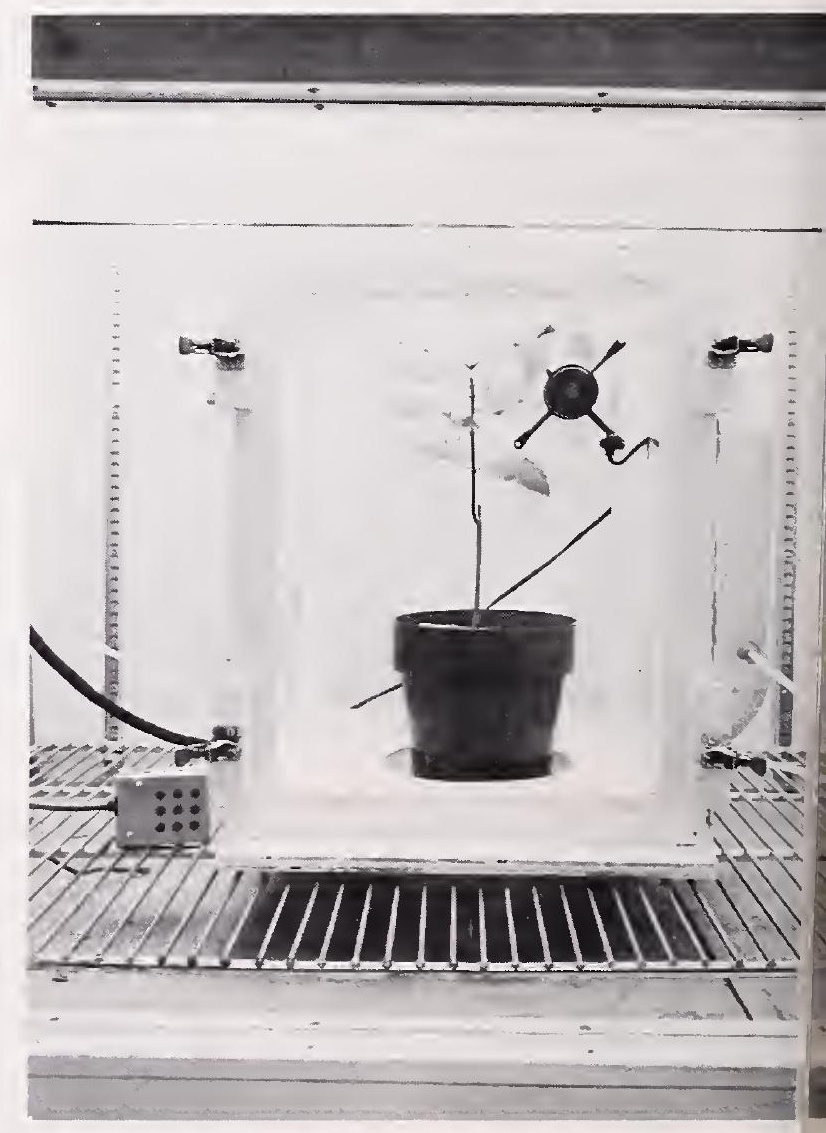

Viewing the fumigation chamber inside the growth chamber.

In future work with these chambers, Forest Service scientists plan to study how air pollution might be affecting all stages of growth and development of trees, including seed production and germination. Compounds that may reduce air pollution damage will also be investigated. 
